\title{
Physico-chemical and Concentration of Heavy Metals Analyses in Virgin and Used Lubricating Oils: A Spectroscopy Study
}

\author{
Boadu Kwasi Opoku ${ }^{1,2,3}$, Joel Ogbonna Friday ${ }^{1,3}$, Essumang David Kofi ${ }^{2}$, \\ Evbuomwan Benson Osa ${ }^{3}$ \\ ${ }^{1}$ World Bank Africa Centre of Excellence, Institute of Petroleum Studies, University of Port Harcourt, Port Harcourt, Nigeria \\ ${ }^{2}$ Department of Chemistry, University of Cape Coast, Cape Coast, Ghana \\ ${ }^{3}$ Department of Chemical Engineering, University of Port Harcourt, Port Harcourt, Nigeria
}

Email address:

koboadu@ucc.edu.gh (B. K. Opoku),boadu.kwasi@aceuniport.org (B. K. Opoku)

\section{To cite this article:}

Boadu Kwasi Opoku, Joel Ogbonna Friday, Essumang David Kofi, Evbuomwan Benson Osa. Physico-chemical and Concentration of Heavy Metals Analyses in Virgin and Used Lubricating Oils: A Spectroscopy Study. American Journal of Applied Chemistry.

Vol. 7, No. 6, 2019, pp. 175-179. doi: 10.11648/j.ajac.20190706.14

Received: November 8, 2019; Accepted: November 25, 2019; Published: December 9, 2019

\begin{abstract}
As a result of the changes that occur during their use, lubricating oils from automobiles tend to differ in terms of their physical and chemical composition from virgin and used lubricating oils. The analyses of the heavy metals distribution, contaminants and physicochemical parameters of the virgin and used lubricating oils will guide us to select the possible processes that can alter the oil composition. This research examines the heavy metals distribution, contaminants and physicochemical parameters of the virgin and used lubricating oils using Atomic Adsorption Spectrometer for 7 elements using various ASTM D methods. The results obtained shows that there were significant differences in the virgin and used lubricating oils. The deleterious effects of heavy metals, contaminants and physicochemical parameters on the environment have been known for a while. These contaminants not only causes environmental problems, they also have bio-accumulation effects on living organism, poisoning and fouling of catalyst as well as corrode processing equipment. This study also presents results showing us that contaminants, heavy metals and physicochemical parameters play a major role in discriminating of lubricating oil samples.
\end{abstract}

Keywords: Heavy Metals, Physicochemical, Oil Analysis, Contaminants, Lubricating Oils

\section{Introduction}

Investigations into the various concentrations of heavy metals and physicochemical parameters present in both virgin and used lubricating oils have been carried out for several years. For example, analysis of heavy metals and physicochemical parameters in lubricating oil has been introduced to detect the failure of engine parts in early-stage prior to major deterioration. Wear metals such as iron $(\mathrm{Fe})$, chromium $(\mathrm{Cr})$, aluminium $(\mathrm{Al})$, lead $(\mathrm{Pb})$ and cadmium $(\mathrm{Cd})$ may indicate wear in engine or any oil-wetted compartment. However for silicon ( $\mathrm{Si}$ ), Sodium (Na) and boron (B) may explain the contamination from dirt and antifreeze that might lead to system failure [1-3]. Many additives elements such as calcium $(\mathrm{Ca})$, phosphorus $(\mathrm{P})$ and zinc $(\mathrm{Zn})$ was blended with oil for metallic detergents, ash-less dispersants, antioxidant, anti-wear, friction modifier and antifoam purposes [4]. Also possible sources of lubricating oils contamination arise from unburnt fuel, carbon particles, and water, acid as well as solid impurities. In spite of impurities, most of the base oil part in the used oil is not exhausted. The chemical composition of the lubricating oil is usually preserved to a large extent because of the high stability of the heavy compounds contain in the base oil [5]. For instance, in Malaysia, a guideline on standard and specifications of recovered used oil was established in year 2009 [6]. Typical used oil contains physical and chemical impurities that can affect living creatures and classified as scheduled waste under First Schedule of the Environment Quality Regulation 2005 [6]. The recycling of used lubricating oil may be an appropriate 
and cheap alternative to and burn incineration [7]. Several recycling methods have been tried for refining of used lubricating oils. In the course of the refining, the chemical, physical and mechanical impurities are removed with through the following methods; distillation, acidic refining, adsorption treatment with activated carbon, hydrogenation etc. These processes come out with different yields and products. Nowadays, several analytical types of equipment are widely used to determine the presence and concentration of heavy metal and contaminants pollution on the environment such as Atomic Adsorption Spectrophotometer (AAS) and Inductively Coupled Plasma-Optical Emission Spectrometer (ICP-OES). The purposes of this research work were to use Atomic Adsorption Spectrophotometer to determine the concentration of 7 heavy metals in virgin and used lubricating oils and to study the differentiation between the physicochemical parameters on oils samples.

\section{Materials and Methods}

\subsection{Quality Control}

Calibration of the Buck model 205, model 4 AAS was done using mixed calibration standard solutions prepared from pure BDH AnalaR grade salt of each element viz. $10 \mathrm{mg} / \mathrm{kg}$ of Copper $(\mathrm{Cu})$, Iron $(\mathrm{Fe})$, Zinc $(\mathrm{Zn})$, Cadmium $(\mathrm{Cd})$, Lead $(\mathrm{Pb})$, Chromium $(\mathrm{Cr})$ and Magnesium $(\mathrm{Mg})$ and the recovery ranged from $85 \%$ to $95 \%$. All the reagents used were of BDH AnalaR grade and the solvents used were triply distilled [8]. All the glassware and sample bottles were cleaned.

\subsection{Sample Collection}

In this study, used lubricating oils were collected from car oil change shops (lube bay) at East-west Road, Port Harcourt, Nigeria after $3500 \mathrm{~km}$ and $5000 \mathrm{~km}$ in use. The used lubricating oils were collected in containers of 5 Litres each. They were stored for several days to settle large suspended particles before using it for the next steps. The used lubricating oils were filtered to remove all impurities such as metal chips, sand, dust, particles and micro impurities that are present. The type of base oil (virgin oil) used in this study was 5litres Total Quartz 5000 20W-50 manufactured by Total Petroleum. This type of lubricating oil was selected because it is suitable for use in gasoline and diesel engines particularly passenger cars and light industrial vehicles. It can also be used in all operating conditions such as heavy city traffic, road and motorways irrespective of the season. Perfectly adapted to vehicles equipped with catalysts and using unleaded fuel or liquefied petroleum gas.

\section{3. $p H$}

The oils $\mathrm{pH}$ were determined with the use [9] and also confirm with $\mathrm{pH}$ indicator (meter). Apparatus used were $50 \mathrm{ml}$ beaker and $\mathrm{pH}$ indicator. $30 \mathrm{ml}$ of the oil samples were measured into $50 \mathrm{ml}$ beakers and vigorously stirred. The $\mathrm{pH}$ was obtained using a $\mathrm{pH}$ indicator and read after $3 \mathrm{~s}$. It was cross-matched with the colour scale.

\subsection{Specific Gravity}

The specific gravity of both the virgin and used lubricating oil samples was determined using Pycnometry Instrument and affirm with [10] ASTM standard test method for density, relative density, or API gravity of crude petroleum and liquid petroleum products by hydrometer method.

\subsection{Dynamic Viscosity}

The dynamic viscosity for the virgin and used lubricating oil samples was ascertain based on API gravity of crude petroleum and liquid petroleum products by hydrometer method and confirm with [11] ASTM Standard Test Method for Kinematic Viscosity of Transparent and Opaque Liquids and Calculation of Dynamic Viscosity.

\subsection{Kinematic Viscosity}

Kinematic viscosities of the virgin and used lubricating oil samples were measured at $37^{\circ} \mathrm{C}$ with Canon-Fenske Routine viscometers or Canon-Fenske Opaque viscometers according to [11], standard test method for transparent and opaque liquids respectively.

\subsection{Water Content}

The water content of the virgin and used lubricating oil samples were determined to assess the amount of water contaminant resulting from condensation and combustion chamber blow-by gases into crankcase using [12] ASTM standard test method was used for water content determination.

\subsection{Sediment Content}

Sediments content of the virgin and used lubricating oil samples were determined to ascertain the level of contamination using [13] ASTM Standard Test Method for Water and Sediment in Middle Distillate Fuels by Centrifuge.

\subsection{Digestion and Elemental Analysis}

According to the acid digestion method used by [3, 8, 14], a total of $0.5 \mathrm{~g}$ each of the fine oil samples was weighed into a Kdjedahl digestion flask and $5 \mathrm{~mL}$ concentrated $\mathrm{H}_{2} \mathrm{SO}_{4}$ was added to the oil sample and heated in a fume hood until the oil sample started to char. Then, $10 \mathrm{ml}$ of $\mathrm{H}_{2} \mathrm{O}_{2}$ was added to the charred mixture and was heated for $5 \mathrm{~min}$ and the mixture turned colourless when the digestion was completed. The used and virgin lubricating oil (control) samples were digested using the same method. Each digest was transferred into a $100 \mathrm{ml}$ volumetric flask and made up to the mark was transferred into a cleaned plastic container for AAS analysis. The digested samples were analysed using Buck model 205, model 4 atomic absorption spectrophotometer (ChemTech Analytical, Unified National Inventory Database 066332) at the Pollution Control and Environmental Management Limited, Port Harcourt, Nigeria. 
Table 1. Physicochemical parameters of the various samples.

\begin{tabular}{lllll}
\hline Parameters & Units & Sample A & Sample B & Control (Virgin) \\
\hline pH @ 29 $9^{\circ} \mathrm{C}$ & & 5.0 & 5.0 & 6.0 \\
Specific gravity @ 29 29 & & 0.89 & 0.89 & 0.88 \\
Dynamic viscosity @ 27 $27^{\circ} \mathrm{C}$ & $\mathrm{cP}$ & $300+$ & $300+$ & $300+$ \\
Kinematic viscosity @ 27 $27^{\circ} \mathrm{C}$ & $\mathrm{cSt}$ & $337+$ & $337+$ & $341+$ \\
Basic Sediment \& Water & & & & 100.0 \\
Oil & $\%$ & 100.0 & 99.9 & 0.0 \\
Water & $\%$ & 0.0 & 0.1 & 0.0 \\
Sediments & $\%$ & 0.0 & 0.0 & \\
\hline
\end{tabular}

Table 2. Concentration levels of various elements present.

\begin{tabular}{lllll}
\hline Parameters & Units & Sample A & Sample B & Control (Virgin) \\
\hline Copper $(\mathrm{Cu})$ & $\mathrm{ppm}$ & 0.24 & 0.21 & $<0.001$ \\
Iron $(\mathrm{Fe})$ & $\mathrm{ppm}$ & 4.61 & 3.33 & 1.49 \\
Zinc $(\mathrm{Zn})$ & $\mathrm{ppm}$ & 19.5 & 14.8 & 2.83 \\
Cadmium $(\mathrm{Cd})$ & $\mathrm{ppm}$ & 0.02 & 0.03 & 0.03 \\
Lead $(\mathrm{Pb})$ & $\mathrm{ppm}$ & 0.53 & 1.45 & 0.97 \\
Chromium $(\mathrm{Cr})$ & $\mathrm{ppm}$ & 0.39 & 0.45 & 0.39 \\
Magnesium $(\mathrm{Mg})$ & $\mathrm{ppm}$ & 5.10 & 20.06 & 37.4 \\
\hline
\end{tabular}

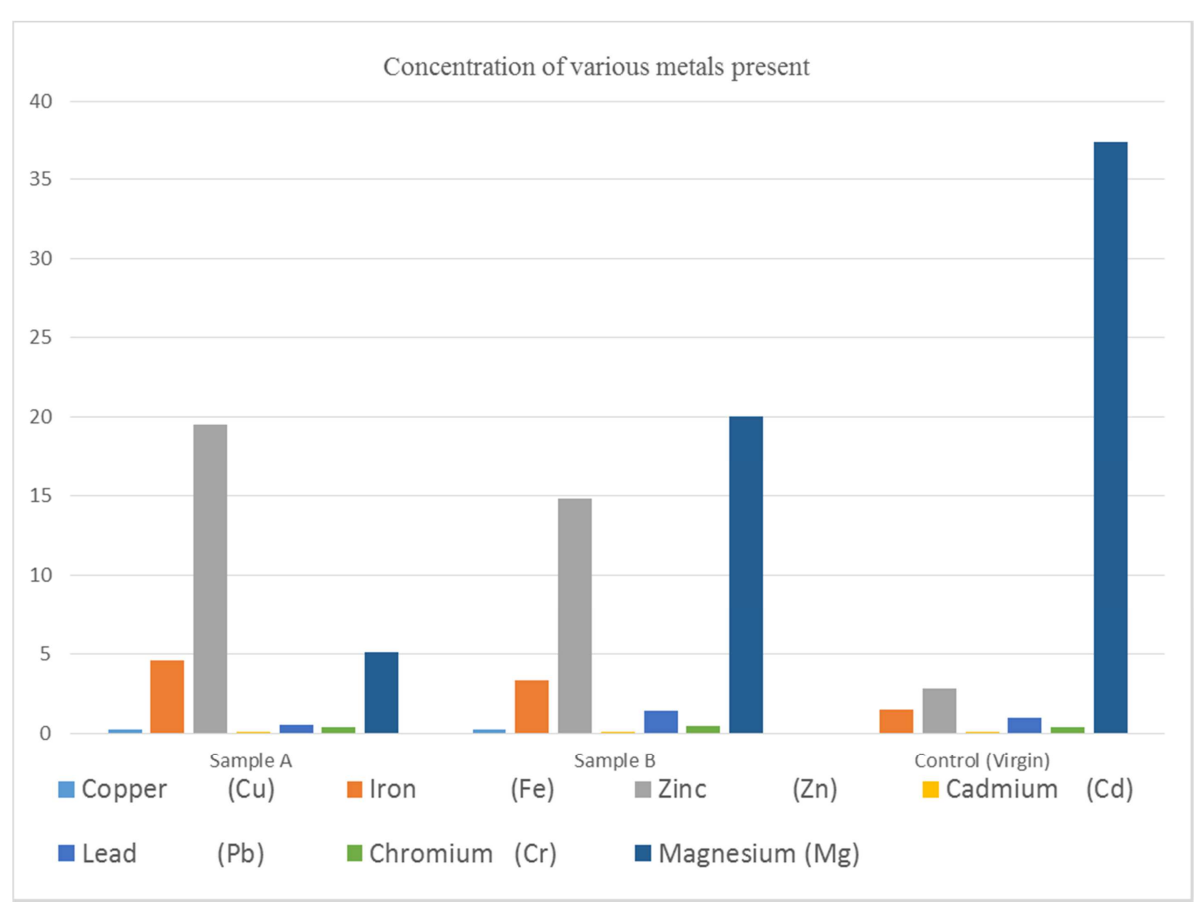

Figure 1. Graph of the concentration of various metals present.

\section{Results and Discussion}

The physicochemical and concentration of heavy metals analyses in virgin and used lubricating oils: a spectroscopy study was carried out. The results are shown in tables 1,2 and figure 1 . The results are then discussed under the following properties of lubricants.

$\mathrm{pH}$ : From Table 1, it can be noticed that the acidic $\mathrm{pH}$ values were found in the used lubricating oil compared to that of the virgin lubricating oil. Because acid corrosion is caused by hydrogen ions $(\mathrm{H}+)$, the measurement of their concentration gives a good indication of how corrosive an oil is becoming. Base (virgin) oil normally has a $\mathrm{pH}$ range 7-8 which decreases steadily over time.
However, the $\mathrm{pH} 6.0$ recorded on the virgin oil samples might be due to the presence of synthetic additives present in the lubricating oil to improve its performance. At a certain point, the $\mathrm{pH}$ begins to decrease more rapidly and it's at this point when the oil needs to be changed $[15,16]$.

Specific Gravity: From the results obtained in Table 1, the specific gravity of the used lubricating oil samples was 0.89 while that of the virgin oil was 0.88 . Specific gravity is influenced by the chemical composition of the oil. An increase in the number of aromatic compounds in the oil results in an increase in the specific gravity, while an increase in the saturated compounds results in decrease in specific gravity [4, 5, 17]. Used lubricating oil samples specific gravity increases with the presence of increasing amounts of solids in the used oil. One per cent of the weight of solids in 
the sample can raise the specific gravity by 0.007 [18].

Dynamic viscosity: From the results obtained after the analyses of both the virgin oil and used oil samples the dynamic viscosity at $27^{\circ} \mathrm{C}$ remains the same. This indicates the dynamic viscosity has no positive correlation on both virgins and used lubricating oil samples [19].

Kinematic Viscosity: Kinematic viscosity at $27^{\circ} \mathrm{C}$ for all the samples were determined. From the results it shows that samples A\&B have values of $337+$ while that of control (virgin) oil was $341+$. The lower values obtained in the used lubricating oil samples indicates the destructive effects of sulphuric acid on the oil. Kinematic viscosity and viscosity, in general, are the most important consideration in choosing lubricating oils. The strength of the oil firm is approximately proportional to its viscosity which determines the thickness of the layer of oil between the metallic surfaces in reciprocal movement [20, 21]. From Table 1, it was observed that the used lubricating oil samples have lost their kinematic viscosity values. This may be due to contamination resulting from thermal degradation effect of molecular constituents of the base oil [17].

Water and sediment contents: After the analyses shown in table. 1, it was observed that there were no sediments contents in all the samples. However, trace amount of water content in sample B was found. The water content found in sample B can lead to corrosion of the crankcase and other problems in the engine. For example, the water and sediment content of lubricating oil is significant because it can cause corrosion of equipment and problems of processing [22, 23].

Elemental Metals: Several lubricating oils constituents contains metallic elements that have been added to it to improve efficiency. Generally, the presence of metals in lubricating oils is considered as contaminants that should be removed completely in order to produce suitable base oil for producing new virgin oil $[24,25]$. From the analyses, the concentration of 7 heavy metals such as copper, $(\mathrm{Cu})$, Iron, $(\mathrm{Fe})$, zinc, $(\mathrm{Zn})$, cadmium, $(\mathrm{Cd})$, lead, $(\mathrm{Pb})$, chromium, $(\mathrm{Cr})$ and magnesium, $(\mathrm{Mg})$ in each of the two lubricating oil used and virgin oil samples are presented in Table 2.

From Table 2, the concentration of $\mathrm{Mg}$ in the virgin decrease from 37.4 ppm to $20.06 \mathrm{ppm}$ for sample B and 5.10 ppm for sample A respectively. The high concentration of $\mathrm{Mg}$ in the virgin oil makes it better because the oil is more viscous by virtue of high concentration of $\mathrm{Mg}$ and thus prevents wear or corrosion. The decrease in $\mathrm{Mg}$ concentration also indicates that $\mathrm{Mg}$ is consumed as suggested in the literature $[25,26]$.

The presence of wear heavy metals in both virgin and used lubricating oil samples were observed, though varying in concentrations. The highest value of $\mathrm{Pb}(1.45 \mathrm{ppm})$ and $\mathrm{Cr}$ $(0.45 \mathrm{ppm})$ were obtained for used lubricating oil sample $\mathrm{B}$, $\mathrm{Pb}(0.53 \mathrm{ppm})$ and $\mathrm{Cr}(0.39 \mathrm{ppm})$ were ascertain for used lubricating oil sample A respectively. The value for lead in virgin lubricating oil sample is $(0.97 \mathrm{ppm})$ which is in line with that reported by [1].

However, the Cr content of 0.45 ppm of used oil sample B was a bit higher than the virgin oil sample and used oil sample A respectively as suggested by literature $[1,17]$.
Also, from Table 2, the concentration of $\mathrm{Zn}$ increases significantly from virgin to the used lubricating oil samples respectively as follows: $\mathrm{Zn}$ in virgin oil was $(2.83 \mathrm{ppm})$, used lubricating oil samples B and A are (14.8 ppm) and (19.5 ppm). A similar pattern had been reported in the literature by $[2,3]$.

From the results obtained in Table 2, there were increased in wear heavy metal $\mathrm{Fe}$ in the used lubricating oils samples B] (3.33 ppm) and A (4.61 ppm) compared to the virgin oil sample (1.49 ppm) which indicates cylinder liners, piston, rings, ball roller bearings of gear wear [27]. It was not surprising as the cars from where the used lubricating oil samples were obtained were more than 10 years old since the date of manufacture.

Finally, from the results obtained in Table 2, there was no significant difference in the values of $\mathrm{Cd}$ recorded in both the virgin $(0.03 \mathrm{ppm})$ and used lubricating oil samples A (0.02 $\mathrm{ppm})$ and $\mathrm{B}(0.03 \mathrm{ppm})$ respectively. $\mathrm{Cd}$ is introduced in the lubricating oil as a contaminant during use. Based (virgin) oils are normally free from cadmium [5, 28]. However, the trace amount detected might be coming from the additives introduced into the lubricating oils to enhance its performance.

\section{Conclusions}

In this study, it was observed that there was a significant increase in the concentration of heavy metals in the used lubricating oil compared to that of virgin lubricating oil. It was also established that the high concentration of heavy metals such as copper, $(\mathrm{Cu})$, Iron, $(\mathrm{Fe})$, zinc, $(\mathrm{Zn})$, cadmium, $(\mathrm{Cd})$, lead, $(\mathrm{Pb})$, chromium, $(\mathrm{Cr})$ and magnesium, $(\mathrm{Mg})$ are dangerous to living things and the environment contained in the used oils disposed. Therefore, the high concentration of these heavy metals indicates danger to life in areas when used lubricating oils are not properly managed and disposed. This work also shows that virgin lubricating oil produced by manufactures investigated contain required physio-chemical parameters good for lubricating purposes.

\section{References}

[1] V. Pelitli, Ö. Doğan and H. J. Köroğlu (2017). Waste oil management: Analyses of waste oils from vehicle crankcases and gearboxes, Global J. Environ. Sci. Manage., 3 (1): 11-20, DOI: 10.22034 /gjesm.2017.03.01.002.

[2] Temitayo E. Oladimeji, Jacob A. Sonibare, James A. Omoleye, Moses E. Emetere and Francis B. Elehinafe, (2018). A Review on Treatment Methods of Used Lubricating oil, International Journal of Civil Engineering and Technology, 9 (12), pp. 506-514.

[3] Boadu, K. O; Joel, O. F.; Essumang, D. K. and Evbuomwan, B. O. (2019). A Review of Methods for Removal of Contaminants in Used Lubricating Oil, Chemical Science International Journal, 26 (4): 1-11, 2019; Article no. CSIJ. 48620, SCIENCEDOMAIN international www.sciencedomain.org. 
[4] Bamiji Z. Adewole, Joshua O. Olojede, Hakeem Ayodele Owolabi and Olaoluwa R. Obisesan (2019). Characterization and Suitability of Reclaimed Automotive Lubricating Oils Reprocessed by Solvent Extraction Technology, Recycling, 4, 31; DOI: 10.3390/recycling4030031 www.mdpi.com/journal/recycling.

[5] Bright Kwakye-Awuah, Ralph Kwakye, Baah Sefa-Ntiri, Isaac Nkrumah, Elizabeth Von-Kiti and Craig Williams (2018). Comparison of the Recycling Efficiency of Metakaolin and Laboratory-Synthesized Zeolite Types LTA and LSX on Used Lubricant Engine Oil, Applied Physics Research; Vol. 10, No. 4; 2018 ISSN 1916-9639 E-ISSN 1916-9647, Published by Canadian Center of Science and Education.

[6] Munirah, A. Z.; Kamaruzaman, W.; Ahmad, W.; Retnam, A.; $\mathrm{Ng}$ Catrina (2015): Concentration of heavy metals in virgin, used, recovered and waste oil; a spectroscopic study, Procedia Environmental Sciences 30, pp: 201-204.

[7] Syeda Azeem Unnisa and Malek Hassanpour (2017). Development circumstances of four recycling industries (used motor oil, acidic sludge, plastic wastes and blown bitumen) in the world, Renewable and Sustainable Energy Reviews, 72 (2017) 605-624.

[8] Adebiyi, F. M.; Ayinde, O. B.; Odebunmi, A. O.; Adeyefa, O. M.; (2014): The reclamation of fine lubricating oil from flat lubricating oil using a combination of activated animal charcoal and amberlite, Petroleum Science and Technology, (32), pp: 162-169.

[9] ASTM D7946 - 14 (2014). Standard Test Method for Initial $\mathrm{pH}$ (i-pH)-Value of Petroleum Products, ASTM International, West Conshohocken, PA, USA, www.astm.org.

[10] ASTM D4052 - 18a (2018). Standard Test Method for Density, Relative Density, and API Gravity of Liquids by Digital Density Meter, ASTM International, West Conshohocken, PA, USA, www.astm.org.

[11] ASTM D445 - 19 (2019). Standard Test Method for Kinematic Viscosity of Transparent and Opaque Liquids and Calculation of Dynamic Viscosity, ASTM International, West Conshohocken, PA, USA, www.astm.org.

[12] ASTM D6304 - 16e1 (2016). Standard Test Method for Determination of Water in Petroleum Products, Lubricating Oils, and Additives by Coulometric Karl Fischer Titration, ASTM International, West Conshohocken, PA, USA, www.astm.org.

[13] ASTM D2709 - 16 (2016). Standard Test Method for Water and Sediment in Middle Distillate Fuels by Centrifuge, ASTM International, West Conshohocken, PA, USA, www.astm.org.

[14] McKenzie, T., (1981). Atomic absorption spectrophotometry for the analysis of wear metals in oil samples, Varian Instruments at Work, Varian atomic Absorption AA-10, Techtron Pty., Ltd., Australia, pp: 1-9.

[15] Ball, P. G. (1998): New pH Test Offers Benefits over TAN/TBN, Practicing Oil Analysis, Vol. 1, No. 2, Noria.

[16] I. J. Ani, J. O. Okafor, M. A. Olutoye and U. G. Akpan (2015). Effects of Process Variables and a Comparative Study of Methods for Transfer Oil Production from Spent Engine
Oil, British Journal of Applied Science \& Technology, 9 (1): 65-76, Article no. BJAST. 2015.247 ISSN: 2231-0843, SCIENCEDOMAIN international www.sciencedomain.org.

[17] Ihsan, H.; Talal, Y.; Sardasht, R.; (2013): Recycling of wastes engine oils using a new washing agent, Energies, (6), pp: 1023-1049.

[18] Forsthoffer, W. E., (2011): Lube, seal and control oil system best practices. In Forsthoffer's Best Practice Handbook for Rotating Machinery, $1^{\text {st }}$ ed., Elsevier: Oxford, UK, pp. 347468.

[19] E. Epelle, Y. Lukman and A. J. Otaru (2016). A comparative study of the solvent powers of phenol, furfural and NMP in improving the viscosity index of spent lubricating oil, International Research Journal on Engineering, Vol. 3 (1), pp. 008-024, http://www.apexjournal.org (C2016 Apex Journal International.

[20] Eman, A. E, Shoaib, A. M., (2012), Re-refining of used lube oil. II- by Solvent/Clay and Acid/Clay-Percolation Processes, ARPN Journal of Science and Technology, 2, (11): 1-8.

[21] C. T. Pinheiro; V. R. Ascens ao; C. M. Cardoso; M. J. Quina; L. M. Gando-Ferreira (2017). An overview of waste lubricant oil management system: Physicochemical characterization contribution for its improvement, Journal of Cleaner Production, 150, pp. 301-308.

[22] Kishore Nadkarmi, R. A. (2007): Water and Sediments in Crude Oil. "In Guide to ASTM Test Methods for Analysis of Petroleum Products and Lubricants" $2^{\text {nd }}$ ed.; ASTM International; West Conshohocken, PA, USA, www.astm.org.

[23] M. Pazoki and B. Hasanidarabadi (2017). Management of toxic and hazardous contents of oil sludge in Siri Island, Global J. Environ. Sci. Manage., 3 (1): 33-42, DOI: 10.22034/gjesm.2017.03.01.004.

[24] Aucelio, R. Q.; de Souza, R. M.; de Campos, R. C.; Mieley, N.; Da Silva, C. L. P. (2007): The determination of trace metals in lubricating oils by atomic spectrometry. Spectrochim. Acta Part B At. Spectrosc, 62, pp. 952-961.

[25] Chun Yang, Zeyu Yang, Gong Zhang, Bruce Hollebone, Mike Landriault, Zhendi Wang, Patrick Lambert, Carl E. Brown (2016). Characterization and differentiation of chemical fingerprints of virgin and used lubricating oils for identification of contamination or adulteration sources, Fuel, 163, pp. 271-281.

[26] Henry Mensah-Brown (2015). Re-Refining and Recycling of Used Lubricating Oil: An Option for Foreign Exchange and Natural Resource Conservation in Ghana, ARPN Journal of Engineering and Applied Sciences, Vol. 10. (2), pp. 797-801.

[27] R. U. Owolabi; A. A. Akinola; O. A. Oyelana and M. K. Amosa (2017). Some Physico-Chemical and Adsorptive Reclamation Strategies of Spent Automobile Engine Lubricating Oil; Journal of Engineering Research, Volume 22 (1), pp. 98-106.

[28] Robbins, W. K.; Walker, H. H,; (1975): Analysis of petroleum for trace metals. Determination of trace quantities of cadmium in petroleum by atomic absorption spectrometry. Anal. Chem. (47), $p p:$ : 1269-1275. 